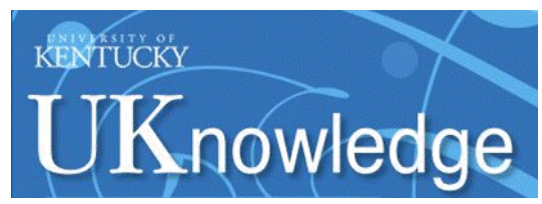

University of Kentucky

UKnowledge

$5-6-2019$

\title{
Measurement of Bystander Actions in Violence Intervention Evaluation: Opportunities and Challenges
}

\author{
Heather M. Bush \\ University of Kentucky, heather.bush@uky.edu \\ Samuel C. Bell \\ University of Kentucky, samuel.bell@uky.edu \\ Ann L. Coker \\ University of Kentucky, ann.coker@uky.edu
}

Follow this and additional works at: https://uknowledge.uky.edu/biostatistics_facpub

Part of the Biostatistics Commons, Domestic and Intimate Partner Violence Commons, and the Obstetrics and Gynecology Commons

Right click to open a feedback form in a new tab to let us know how this document benefits you.

\section{Repository Citation}

Bush, Heather M.; Bell, Samuel C.; and Coker, Ann L., "Measurement of Bystander Actions in Violence Intervention Evaluation: Opportunities and Challenges" (2019). Biostatistics Faculty Publications. 52. https://uknowledge.uky.edu/biostatistics_facpub/52

This Article is brought to you for free and open access by the Biostatistics at UKnowledge. It has been accepted for inclusion in Biostatistics Faculty Publications by an authorized administrator of UKnowledge. For more information, please contact UKnowledge@lsv.uky.edu. 


\section{Measurement of Bystander Actions in Violence Intervention Evaluation: Opportunities and Challenges}

\section{Digital Object Identifier (DOI)}

https://doi.org/10.1007/s40471-019-00196-3

\section{Notes/Citation Information}

Published in Current Epidemiology Reports, v. 6, issue 2.

This is a post-peer-review, pre-copyedit version of an article published in Current Epidemiology Reports.

The final authenticated version is available online at: https://doi.org/10.1007/s40471-019-00196-3 
Published in final edited form as:

Curr Epidemiol Rep. 2019 ; 6(2): 208-214. doi:10.1007/s40471-019-00196-3.

\title{
Measurement of bystander actions in violence intervention evaluation: Opportunities and Challenges
}

\author{
Heather M. Bush, PhD, \\ University of Kentucky, College of Public Health, Lexington, KY USA \\ Samuel C. Bell, JD, \\ University of Kentucky, College of Medicine, 800 Rose St., Pavilion H, Room C359, Lexington, KY \\ USA 40536 \\ Ann L. Coker, PhD \\ University of Kentucky, College of Medicine, 800 Rose St., Pavilion H, Room C361, Lexington, KY \\ USA 40536
}

\begin{abstract}
Purpose of review-This review discusses design and methodological challenges specific to measuring bystander actions in the evaluation of bystander-based violence prevention programming. "Bystanders" are defined as people who are present immediately before, during and/or after a violent event, but are not a perpetrator nor the intended victim. Bystander-based violence prevention programs seek to prevent or mitigate violent events by empowering bystanders to intervene on acts of violence and social norms that promulgate violence.
\end{abstract}

Recent findings-Effective bystander-based violence prevention programs demonstrate increased bystander intentions, actions, and attitudes [Bringing in the Bystander, ${ }^{12}$ iSCREAM $^{33}$; The Men's Project; ${ }^{20}$ and Green Dot, $\left.{ }^{3}\right]$ lowered violence acceptance scores ${ }^{19,21,22,23,36}$ and reduced sexual violence perpetration and victimization. ${ }^{3 \cdot \bullet, 6,20}$ However, bystander-based violence prevention programs are methodologically challenging to evaluate, due to the wide diversity of programs being implemented and the multifactorial and contextual nature of acts of violence.

Summary-Measures of bystander actions temporally-connected to specific, high-risk opportunities are recommended approaches to capture bystander experiences and address the methodological challenges in measuring bystander actions and evaluating violence prevention programming.

\footnotetext{
Terms of use and reuse: academic research for non-commercial purposes, see here for full terms. http://www.springer.com/gb/openaccess/authors-rights/aam-terms-v1

Corresponding Author: ann.coker@uky.edu; (859)323-6758.

Publisher's Disclaimer: This Author Accepted Manuscript is a PDF file of a an unedited peer-reviewed manuscript that has been accepted for publication but has not been copyedited or corrected. The official version of record that is published in the journal is kept up to date and so may therefore differ from this version.

Conflict of Interest

Heather M. Bush, Samuel C. Bell and Ann L. Coker each declare no potential conflicts of interest.

Human and Animal Rights and Informed Consent

This article does not contain any studies with human or animal subjects performed by any of the authors.
} 


\section{Keywords}

bystander behaviors; bystander intervention; sexual violence; interpersonal violence; dating violence; adolescents; evaluation; bystander efficacy

\section{Introduction}

High rates of sexual violence and other forms of interpersonal violence among student populations in high schools and college have been widely documented. ${ }^{1,2,3,4,5,6,7,8}$ In 2015, the American Association of Universities (AAU) campus climate survey found higher than previously observed rates of nonconsensual, forced, or incapacitated sex. Across the 27 college campuses included in this AAU sample, $11.7 \%$ of students disclosed these forms of sexual violence (SV) since entering college and this rate was $23 \%$ among female undergraduates. $9 \cdot{ }^{9}$ Rates of SV victimization and perpetration were similarly high (18\% and $12 \%$, respectively) among teens. ${ }^{8}$

Existing SV prevention programming have emphasized awareness and risk reduction strategies ranging from information-based programs to those that more actively target violence risk reduction; the target audiences for these programs also differ across campuses. ${ }^{10}$ More recently, a bystander-based violence prevention approach has been recognized by the White House Task Force to Protect Students from Sexual Assault Report (2014) as a 'promising' tool to prevent sexual assaults on campus. ${ }^{11}$ Bystander training provides individuals with skills to reduce risk for violence by (a) recognizing situations that may become violent, (b) intervening both safely and effectively to reduce the likelihood of violence, and (c) speaking out against attitudes that support or condone violent behavior. Through bystander training, these interventions are hypothesized to reduce violence by changing social norms, such as reducing sexual and dating violence acceptance, and increasing bystander intentions and effective actions to disrupt or diffuse potentially violent events. ${ }^{12}$ As such, prevention programs that apply bystander approaches assert that all members of a community have a role to play in preventing violence; everyone has the potential to intervene in potentially risky situations to reduce the risk of violence or speak up when attitudes of violence acceptance are expressed. ${ }^{12}$

Bystander-based interventions involve all members of a community working to change a culture that may silently support the use of violence. The community could be defined to include a college campus, middle or high school, a sports team, or a fraternity or sorority. Because bystander interventions approach participants not as potential victims or perpetrators but as potential allies, both defensiveness and victim-blaming attitudes are reduced. ${ }^{13,14}$ In trainings, individuals are taught how to recognize situations or behaviors that may become violent and to intervene to reduce the likelihood of violence. ${ }^{13}$ While programs differ in strategy and audience, bystander violence prevention programs share a common philosophy that all members of the community have a role in shifting social norms to prevent violence. The ultimate goal is to educate the community to recognize situations that promote violence and to safely and effectively intervene. ${ }^{15}$ Bystander interventions are hypothesized to reduce violent behaviors by increasing willingness and self-efficacy to

Curr Epidemiol Rep. Author manuscript; available in PMC 2020 August 27. 
challenge violence-supportive norms and behaviors in one's peer group ${ }^{2,19}$ and to intervene in risky situations to prevent violence. ${ }^{12,17,18}$ These individual interventions within peer groups diffuse the benefits of training through social networks to produce changes in social norms and behavior at the community level. Hence, the bystander approach to violence prevention is unique in that it engages program participants as possible witnesses to violence rather than potential victims or perpetrators.

Mentors in Violence Prevention (MVP), one of the earliest bystander programs, targeted student-athletes and leaders and has been widely adopted on college campuses. MVP initially focused on men to encourage leadership on issues of gender-based violence, bullying, and school violence. ${ }^{16}$ In 2004, the first empirical evidence of the effectiveness of this approach was published based on college students. ${ }^{13}$ Participation in this bystander intervention focused on improving students' attitudes around rape myths (reducing SV acceptance) and increasing students' bystander efficacy and expressed intent to take action to help others before, during, or after a potential sexual assault. Researchers found preliminary evidence that students who received the bystander training engaged in a greater variety of bystander actions post-training than the students in the control group. Additional evidence suggests that bystander approaches to violence prevention increased bystander intentions, ${ }^{12,17,18}$ promoted positive bystander behaviors, ${ }^{6,19}$ and reduced sexual aggression among college men ${ }^{20}$ and adolescent male athletes. ${ }^{6}$ These results have been supported by additional studies using select groups of students (leaders, athletes, Greek members) and in a multi-campus study. ${ }^{21,22}$

Bystander interventions are being implemented on college and high school campuses using a variety of methods. Coker et al. ${ }^{3 \cdot \bullet}$ demonstrated the effectiveness of the bystander program, Green Dot, to reduce sexual violence perpetration over time in a randomized controlled trial involving 26 high schools. Rutgers University's iScream theater ${ }^{23}$ and the University of California's InterAC ${ }^{24}$ use interactive theater to model pro-social bystander actions to prevent sexual assault. Kleinsasser, Jouriles, McDonald, and Rosenfield ${ }^{25}$ described a successful online intervention focused on bystander action; Salazar, Vivolo-Kantor, Hardin, and Berkowitz ${ }^{26}$ provided evidence using a randomized controlled trial to indicate effectiveness of the online bystander-based training RealConsent, relative to a web-based general health promotion program to reduce sexual violence perpetration and change both knowledge and attitudes supporting sexual violence. Social marketing campaigns have been used on campuses to promote positive social norms and bystander actions. ${ }^{18}$ Elias-Lambert and Black $^{27}$ evaluated the effectiveness of a peer-facilitated bystander training to reduce SV and found this training to be associated with significant reductions in both rape myth acceptance and self-reported sexually coercive behaviors particularly among high risk (fraternity) men. Again, using the peer impact theme, Senn and Forrest ${ }^{28}$ found peer educators to be effective in increasing bystander efficacy, intentions, and proactive bystander behaviors in both male and female college students.

With the wide range of bystander training programs delivered using different modalities, risk groups, and requirements, accurate and thorough evaluation of program effectiveness is essential to realizing the promise of bystander programming to reduce SV among adolescents and young adults. Design and methodologic challenges unique to bystander- 
based program evaluations stem from how bystander actions are hypothesized to reduce violence. Effective training should reduce the trained individual's violence acceptance and increase their bystander intentions and actions. In turn, these individual-level actions should reduce SV within the trained individual's community through diffusion of their bystander actions. A design challenge is the need to measure both trained-individual and communitylevel attitudes, behaviors, and SV indicators over time.

\section{Bystander actions.}

Measuring bystander actions continues to be a key challenge in the evaluation of bystander intervention programming. Approaches to measuring bystander behaviors and actions have evolved from item-level occurrence, ${ }^{29}$ to frequency of behaviors performed, ${ }^{19,34}$ to accounting for opportunity within response options, ${ }^{31}$ to measuring items of both frequency of opportunity to engage in bystander behaviors and frequency of bystander behaviors. ${ }^{31 \cdot \bullet}$

Given the nature of settings in which bystanders might both observe and take action to reduce the potential risk of interpersonal violence, the only individuals who may accurately report on bystander actions are the actor (i.e. the bystander herself/himself), the potential victim, perpetrator, or another who might have witnessed the event. Thus, researchers are restricted to either bystander self-reports or observations by others. While the use of observations by others may help to validate self-reported behaviors, it is unlikely that an observer can recall actions performed by another where the ultimate outcome did not result in a violent or dangerous event. Further, to evaluate bystander interventions, a participant's action needs be linked to training received. An observer may not be aware of training received by the actor, thus a link between training received and bystander actions is unavailable with an observer reporter. Hence, self-report serves as the current 'gold standard' for active bystander behaviors reports.

The initial measures of self-reported bystander behaviors and actions used survey items where participants indicated "Yes" or "No" for whether they employed specific behaviors or actions; these responses were summed to create a scale. ${ }^{12,29}$ For the purposes of evaluation, modifications to these items included frequency responses (e.g., "0 times," " $1-2$ times," "3 - 6 times," and "More than 6 times" for the behavior performed ${ }^{19}$ ). However, a primary task of bystander training is to help trainees (a) recognize or otherwise identify situations that may become violent or abusive and, when recognized, (b) evaluate what actions the trainee might do alone or with others to reduce the potential for violence or abuse, and (c) weigh barriers to actions against consequences of inaction. Surveys should ideally measure not only whether the participant reported using actions but also, importantly, whether the participant had the opportunity to intervene effectively.

\section{Capturing Bystander Opportunity}

Within the college evaluation of Coker et al. ${ }^{19}$ the addition of a "No opportunity" response option significantly reduced the number of reported " 0 times" reports. Asking only about whether the participant used bystander actions in a specified setting indicates that no action was taken but a 'no' response can have multiple meanings. A 'no' response may indicate that the participant had (a) 'no opportunity' for action because they did not see the situation, 
(b) they did not recognize the situation as risky, or (c) they had an opportunity, recognized the situation as risky yet chose not to take action, potentially due to a barrier. Ideally, effective prevention programs with a bystander model raises awareness for opportunities to act, and thus bystander behaviors will increase. Because an aspect of training is to make community members aware of potential situations that require action, recognizing opportunity has been viewed as an additional measure of training efficacy. ${ }^{13}$

The complexity of the opportunity construct is not fully captured by an additional single response option, however. This is resolved by capturing, separately, both frequency of opportunity and bystander actions. This essentially doubles the number of items, lengthening surveys and potentially confusing participants with similar sets of items. In the evaluation of student populations, shorter and more efficient surveys are important for maximizing response rate. One potential compromise is to limit the number of behavior-opportunity pairs to those most essential to determining the effectiveness of the program. Although scenarios involving greatest risk may be of primary interest, selecting these high risk situations may not be common experiences and may exacerbate the issues of counting behaviors in the context of "no opportunity." More rare events (e.g. physically forced sex) will have a greater number of "no opportunity" responses and will result in small bystander behavior or action scores. Evaluating changes or making comparisons when scores are very small makes it difficult to provide meaningful conclusions about the effectiveness of a bystander intervention program.

Within bystander programs, the 3-Ds are cited as the categories of bystander action: direct action, create a distraction, or delegate or engage others. However, there are many actions within the 3-Ds that could be used to diffuse a situation and reduce the risk of violence. These are dependent on the age group and social setting of potential active bystander(s), perpetrator, and victim. Providing a detailed listing of the wide range of options may be feasible but will be burdensome to those completing surveys. An approach to addressing this challenge is to use reports of risky situations more commonly observed in the given setting(s) and use this abbreviated list to query active bystander behaviors. The addition of a question regarding the potential bystander doing anything else is an approach to capturing other related bystander behaviors without an exhaustive listing of potential bystander scenarios. Using the headings of direct action, distraction and delegation might also be another strategy to help the participant accurately recall their actions. Recalling the opportunity, however, is contingent on (a) recognizing the situation as potentially risky and (b) being present in the typical social setting in which the bystander opportunity presents itself.

\section{Individual bystander experiences and perspectives}

While bystander intervention programs strive to provide individuals with skills to intervene, other violence prevention programs may suggest risk reduction by avoiding social settings where alcohol or other substances are available. At the individual level, avoiding risky situations is a good strategy to reduce personal risk of violence, abuse, or substance misuse. However, bystander approaches are only effective when trained bystanders are present to intervene. Having a risk avoidant bystander will reduce the opportunities to make use of this 
training and will limit effectiveness for violence prevention. To account for the potential for individuals to avoid or partake in higher risk situations, evaluators may opt to ask participants about the size of their social networks and the frequency of social interactions that could increase opportunities to intervene. Similarly, additional individual characteristics may also be collected to help identify trainees who have a natural propensity to intervene or who benefit most from practiced skill-building. As such, analyses of program efficacy for different and potentially higher risk groups are also encouraged.

Examining program effectiveness within subgroups obviously requires a larger sample. Analyzing intervention efficacy separately among male and female participants, for example, may require a doubling of the sample size to provide sufficient power within each subgroup. When such effect modification analyses are based on attributes less commonly occurring in a population (e.g., sexual minority, experiencing child abuse, substance abuse) the needed sample size from any particular group may require alternative sampling strategies, which could alter the representativeness of the overall sample, i.e., oversampling may require weighting for accurate estimates.

Beyond determining whether the participant took action, an emerging element of evaluation is the degree of success of the action. ${ }^{32}$ Understanding whether and how an action effectively diffused a potentially dangerous situation, or provided support to a potential victim in the presence of violence, may be the ultimate measure of intervention success. Unfortunately, the result of a particular action is a subjective assessment and may not be something that the participant can accurately answer. The potential victim and perpetrator may be able to best provide this information. Future evaluations may choose to address this challenge by asking participants about their own experiences within risky situations and whether others intervened to diffuse or otherwise prevent violence or abuse. Adding questions on the efficacy of such actions could provide more information on the diffusion of training through a community and indicate the perception of others' bystander efficacy. Supplementing quantitative assessments of bystander behaviors and actions with qualitative measures associated with actions and outcomes may additionally provide context, new bystander behavior strategies, and characterizations of what worked effectively and what did not. These additional descriptions provide necessary insight into understanding why individuals might continue or discontinue performing bystander behaviors and actions and how their decisions diffuse violence.

\section{Longitudinal community evaluations}

Bystander training is hypothesized to reduce violence - among other persons in a given community - by reducing violence acceptance and increasing safe and effective bystander behaviors. Trained and untrained participants can report on their attitudes toward violence and their own bystander behaviors, but potential bystanders are not necessarily at lower risk of violence. In fact, active bystanders may be at increased risk of violence if their actions and behaviors are not safe or effective. When the outcomes are changes in attitudes (e.g., violence acceptance, negative attitudes toward women, traditional sex role stereotypes) or bystander efficacy, intentions or actions, the appropriate unit of analysis is the individual who may or may not have received the bystander training. Longitudinal evaluations, where 
individuals are followed over time, are ideally suited for tracking the trajectory of bystander program impact on these outcomes.

In contrast, changes in violence whether measured as experienced (victimization) or used (perpetration) should be considered at the community level (i.e. the appropriate unit of analysis is no longer the trained or untrained individual but the community). Outcomes are community-level violence experiences within the specific communities where individuals were trained (or not). However, community-level bystander actions cannot necessarily serve as a direct measure of intervention effectiveness. Community-level measures of bystander actions aggregate reports of bystander actions of the individuals, providing a measure of the level of bystander actions occurring within the community. Successful interventions reduce community-level violence over time. If violent events indicate missed opportunities for effective bystander action, then reductions in violence also reduce opportunities for bystander action. Community-level evaluations, using bystander actions as an outcome, may suggest null or negative effects if the time-varying effect of community-level violence is not also considered. Measures of bystander actions temporally-connected to specific high risk opportunities might help to address this issue and prevent the misinterpretation of analytic findings.

The efficacy of bystander trainings to reduce sexual violence in communities influenced by the degree of community adoption and implementation. Interventions applied at the community-level often require significant initial and sustained buy-in from key stakeholders. Moreover, bystander training uptake is not immediate and can take time to reach full implementation. Maintaining community enthusiasm and consistent training levels over time also results in varying rates of participation, adherence, and diffusion/saturation. This interdependence between community-level violence (potential opportunity), level of intervention uptake, and bystander actions over time complicates analytic strategies to evaluate intervention efficacy and the causal effects of the intervention on the community.

Temporally sequenced data from individual and community level sources could additionally address mechanisms by which training affects violence acceptance, bystander barriers, intentions, and action to ultimately reduce violent events in a community over longer periods of time. Tracking experiences over time could provide additional insights for strategies to keep bystanders engaged and performing actions. For example, bystanders who experience successful implementation of bystander strategies may continue at the same elevated rate observed post-training. For others, applying bystander behaviors in real-life may present challenges. The ability of bystanders to adapt training to opportunities they face may predict whether efficacious behaviors continue. It is unknown whether, over time, trainees choose to limit exposure to particular opportunities or if trainees become de-sensitized and lose the ability to identify opportunities. As no long-term evaluations measuring bystander actions and opportunity exist, it is unclear how opportunity and efficacious (or lack of) bystander experiences may moderate the potential of bystander training to reduce sexual and interpersonal violence over longer periods of time.

Most evaluations of bystander programming have been short term ( $₫ 2$ months). This is sufficient time to measure short-term changes in violence acceptance or willingness to 
actively bystand, but additional time may be required to see changes in reported use or experiences of violence. If the mechanism for reducing violence is temporally sequenced such that increases in bystander actions and changes to social norms must occur first, evaluations need time to measure training efficacy and yield sustained reductions in violence. Longer trials are difficult to fund and conduct, but much of what we need to understand about how bystander interventions prevent sexual violence and other forms of violence (both victimization and perpetration) can only be captured by following trained individuals over time.

\section{A new approach to address challenges}

For comprehensive, longitudinal evaluations of promising primary prevention strategies, new methodologies are needed to capture training-associated changes in the intentions, frequency, and effectiveness of bystander behaviors within the context of opportunity over time. Asking participants to recall their opportunity and actions in potentially risky situations over several months or year may be onerous except when situations described are rare and impactful. For more commonly occurring bystander situations, a shorter period for survey administration is highly recommended. The shorter period does require more frequent assessment and offers an additional challenge of participant survey fatigue. As an alternative, short 'real-time' surveying with a recall of 1-3 days is a viable option particularly when paired with events linked to higher risk periods.

There is a distinct advantage for evaluating bystander interventions within student populations. Academic calendars are fairly consistent and historical data can be used to identify particular events that are associated with elevated violence risk. As an example, Lindo et al. investigated the rates of reported rape in the context of Division I football games, "which intensify partying among college students." 33 Estimates of rape were highest in the context of football games associated with prominent teams in prominent games (rivals and ranked) by perpetrators who also were college-aged and unknown to the victim, suggesting that 746 additional reports of rape were attributed to football games across 128 universities in a year. ${ }^{33}$ Although college populations have increased risk for sexual violence, other school-based events may heighten (peak) opportunities to intervene (e.g. Spring Break, finals week).

The findings of Lindo et al. echo current gaps in bystander intervention effectiveness research, which express the need to evaluate programming in ways that account for the context and opportunities of bystander behaviors. ${ }^{31}$ Rapid measures of event-based violence risk, and therefore bystander opportunity, are needed to better evaluate and optimize bystander intervention programming. Borrowing from event sampling methodology (ESM), 34,35 which captures ongoing experiences and events by more frequent assessments in naturally occurring environments, we are currently seeking to strategically gather data about individual students' behaviors during these peak opportunity windows for primary prevention. While event sampling methods have been traditionally used in studies that capture temporal changes in mood, sleep, or activity levels, this application improves validity by limiting recall and providing external, environmental context. Using ESM to evaluate bystander behaviors in proximity to pre-identified peak opportunities improves self- 
reports and gains a more comprehensive picture of the student experience, while minimizing participant burden. As smartphones are ubiquitous in this population, short or micro (generally limited to 1-2 questions) surveys are ideally suited for this short, rapid (students can respond on their smartphone and most do within hours of launch), and relevant (the ability to launch surveys in response to peak opportunities provides specific context) evaluation. Moreover, leveraging the event-sampling strategy, it is possible to bookend peak opportunities with booster trainings and assessments. The sequence of strategically crafted intervention messages before a high-risk campus event, combined with a survey launch after the high-risk event, provides a direct measure of training and actions in the context of opportunity.

\section{Conclusions}

Although bystander training has been established as a promising prevention strategy, evidence establishing the long-term effectiveness of bystander training for the primary prevention of sexual violence remains lacking. Studies following students up to one-year post-training found those receiving in-person bystander training reported more frequent bystander behaviors relative to those whose training was limited to a social marketing campaign, but self-reported accounts of bystander behaviors declined for both groups. ${ }^{36}$ Improved measures for bystander opportunity and means to identify specific bystander actions as they occur (as opposed to when researchers query participants) may help explain the trajectory of bystander behaviors over time. ${ }^{36}$

When evaluating bystander effectiveness, the context or opportunity for bystander action is a key feature to ascertain. Therefore, identifying the bystander opportunity (situation, who, where) is critical to measuring the utility of bystander behaviors to prevent sexual violence. 31•• Attempts have been made to measure opportunity in connection with bystander behaviors but these admittedly fall short, given surveys' retrospective nature and their required length to address the range of specific opportunities and each bystander action or inaction. ${ }^{31 \bullet \bullet}$ Moreover, we know very little about the possible negative consequences of bystander actions. Expanding the scope of bystander behavior measures to include preferences of behaviors used, outcomes of bystander interventions, and the perceived benefit or harm to the bystander and the potential victim will provide a more rigorous assessment of bystander intervention program effects.

\section{Acknowledgments}

The authors wish to acknowledge the contributions of Professor Bonnie S. Fisher (University of Cincinnati, College of Criminal Justice) to this paper.

\section{Bibliography}

1. Black MC, Basile KC, Breiding MJ, et al. The National Intimate Partner and Sexual Violence Survey (NISVS): 2010 Summary Report. Atlanta, GA National Center for Injury Prevention and Control, Centers for Disease Control and Prevention; 2011.

2. Coker AL, Bush HM, Fisher BS, et al. Multi-college bystander intervention evaluation for violence prevention. Am J Prev Med. 2016;50:8. 
3••. Coker AL, Bush HM, Cook-Craig PG, et al. Randomized controlled trial testing bystander effectiveness to reduce violence. Am J Prev Med. 2017.Builds on the existing literature by providing effectiveness evidence for bystander intervention programming to reduce sexual violence used (perpetration). The school-randomized trial is the largest RCT to evaluate bystander program effectiveness in high school students. Data from 89,707 surveys were aggregated to make community-level comparisons for intervention $(n=13)$ and control $(n=13)$ schools. In an intent-to-treat analysis, the authors found that school-level reports of sexual violence and sexual harassment used (perpetration) and experienced (victimization) declined over time in intervention schools.

4. Krebs CP, Lindquist CH, Warner TD, Fisher BS, Martin SL. The Campus Sexual Assault (CSA) Study. Washington, DC: U.S. Department of Justice; 2007.

5. Krebs CP, Lindquist CH, Warner TD, Fisher BS, Martin SL. College women's experiences with physically forced, alcohol- or other drug-enabled, and drug-facilitated sexual assault before and since entering college. J Am Coll Health 2009;57:639-47. [PubMed: 19433402]

6. Miller E, Tancredi DJ, McCauley HL, Decker MR, Virata MC, Anderson HA, O'Connor B, Silverman JG. One-year follow-up of a coach-delivered dating violence prevention program: A cluster randomized controlled trial. American journal of preventive medicine. 20137 1;45(1):10812. [PubMed: 23790995]

7. Sargent KS, Jouriles EN, Rosenfield D, McDonald R A high school-based evaluation of TakeCARE, a video bystander program to prevent adolescent relationship violence. J Youth Adolesc. 2017;46(3):633-643. [PubMed: 27942943]

8. Taylor BG, Mumford EA. A national descriptive portrait of adolescent relationship abuse: results from the National Survey on Teen Relationships and Intimate Violence. J Interpers Viol.2016;31(6):963-988.

9••. Cantor D, Fisher WB. Report on the AAU campus climate survey on sexual assault and sexual misconduct. Association of American Universities; 2015.Contribution to the literature as the first large multi-college comparative survey to use the same methodology in measuring the incidence, prevalence, characteristics of incidents, and disclosure of nonconsensual sexual contact (penetration and sexual touching) by tactics (physical force, drugs and alcohol, coercion, absence of affirmative consent). Wide variation in rates were noted across colleges. Sexual assault and misconduct rates are highest among females, sexual minority students, and freshmen. Few incidents were reported to campus authorities. Opportunities for bystander actions were also evaluated. Almost half of the students have witnessed a drunk person heading for a sexual encounter yet most did not try to intervene.

10. McMahon S, Postmus JL, Koenick RA(2011). Conceptualizing the Engaging Bystander Approach to Sexual Violence Prevention on College Campuses. J Coll Stud Dev. 2011;52:115-130. doi:10.1353/csd.2011.0002

11. White House Task Force to Protect Students from Sexual Assault. Not Alone: The First Report of the White House Task Force to Protect Students from Sexual Assault; 2014 https:// www.justice.gov/ovw/page/file/905942/download

12. Banyard VL, Moynihan MM, Plante EG. Sexual violence prevention through bystander education: An experimental evaluation. J Community Psychol. 2007;35:463-81.

13. Banyard VL, Plante EG, Moynihan MM. Bystander education: bringing a broader community perspective to sexual violence prevention. J Community Psychol. 2004;32:61-79.

14. Berkowitz AD Fostering men's responsibility for preventing sexual assault Washington, DC: American Psychological Association, 2002 In Schewe PA (Ed.), Preventing violence in relationships: Interventions across the life span. Washington, DC: American Psychological Association; 2002 pp. 163-196.

15. Moynihan MM, Banyard VL. Community responsibility for preventing sexual violence: a pilot study with campus Greeks and intercollegiate athletes. J Prev Interv Community. 2008;36:23-38. [PubMed: 19042461]

16. Katz J Reconstructing masculinity in the locker room: the Mentors in Violence Prevention Project. Harv Educ Rev. 1995;65(2):163-175. 
17. Moynihan MM, Banyard VL, Arnold JS, Eckstein RP, Stapleton JG. Engaging intercollegiate athletes in preventing and intervening in sexual and intimate partner violence. J Am Coll Health 2010;59:197-204. [PubMed: 21186450]

18. Potter SJ, \& Moynihan MM. Bringing in the bystander in-person prevention program to a US military installation: Results from a pilot study. Mil Med. 2011;176(8):870 10.7205/MILMEDD-10-00483 [PubMed: 21882775]

19. Coker AL, Cook-Craig PG, Williams CM, et al. Evaluation of Green Dot: an active bystander intervention to reduce sexual violence on college campuses. Violence Against Women 2011;17:777-96. [PubMed: 21642269]

20. Gidycz CA, Orchowski LM, Berkowitz AD. Preventing sexual aggression among college men: An evaluation of a social norms and bystander intervention program. Violence Against Women. 2011;17(6):720-742. 10.1177/1077801211409727. [PubMed: 21571742]

21. Banyar VL, Moyniha MM, Crossma MT. Reducing sexual violence on campus: the role of student leaders as empowered bystanders. J Coll Stud Dev. 2009;50(4):446-457.

22. Cares AC, Banyard VL, Moynihan MM, Williams LM, Potter SJ, Stapleton JG. Changing attitudes about being a bystander to violence: translating an in-personal sexual violence prevention program to a new campus. Violence Against Women. 2015;21:65-87. [PubMed: 25540249]

23. McMahon S, Winter SC, Palmer JE, Postmus JL, Peterson NA, Zucker S, Koenick R. A randomized controlled trial of a multi-dose bystander intervention program using peer education theater. Health Educ Res. 2015;30:14.

24. Ahrens CE, Rich MD, Ullman JB. Rehearsing for real life: the impact of the InterACT sexual assault prevention program on self-reported likelihood of engaging in bystander interventions. Violence Against Women. 2011;17(6):760-776. [PubMed: 21628338]

25. Kleinsasser A, Jouriles EN, McDonald R, Rosenfield D An online bystander intervention program for the prevention of sexual violence. Psychol Violence, 2015;5(3):227-235. 10.1037/a0037393 [PubMed: 26240776]

26. Salazar LF, Vivolo-Kantor A, Hardin J, \& Berkowitz A. A web-based sexual violence bystander intervention for male college students: randomized controlled trial. J Med Internet Res. 2014;16(9):203. doi: 10.2196/jmir.3426.

27. Elias-Lambert N, Black BM. Bystander sexual violence prevention program: outcomes for highand low-risk university men. Journal of interpersonal violence. 2016 11;31(19):3211-35. [PubMed: 25944830]

28. Senn CY, Forrest A. "And then one night when I went to class...": The impact of sexual assault bystander intervention workshops incorporated in academic courses. Psychology of Violence. 2016 10;6(4):607.

29. Banyard VL, Plante EG, Moynihan MM. (2005). Rape prevention through bystander education: Bringing a broader community perspective to sexual violence prevention. US Department of Justice, 1-206.

30. McMahon S, Banyard VL, McMahon SM. Incoming college students' bystander behaviors to prevent sexual violence. J Coll Stud Dev. 2015;56(5):488-493.

31••. McMahon S, Palmer JE, Banyard V, Murphy M, Gidycz CA. Measuring bystander behavior in the context of sexual violence prevention: Lessons learned and new directions. Journal of interpersonal violence. 2017 8;32(16):2396-418. [PubMed: 26149679] Contributes to the literature as a compilation of four college-based evaluation experiences. The authors provide approaches, lessons learned, and recommendations for future directions for the evaluation of bystander intervention programming on campuses. The authors recommend that future evaluations must appropriately capture opportunity to intervene, action frequency, and situations and the context of those involved.

32. Krauss A., Jouriles EN, Yule K, Grych JH, Sargent KS, Banyard VL. Adverse consequences to assisting victims of campus violence: initial investigations among college students. J Interpers Viol. 2017; 0886260517746944.

33. Lindo JM, Siminski PM, Swensen ID. College party culture and sexual assault. National Bureau of Economic Research; 2015. 
34. Barrett LF, Barrett DJ. An introduction to computerized experience sampling in psychology. Social Science Computer Review. 2001 5;19(2):175-85.

35. Scollon CN, Prieto CK, Diener E. Experience sampling: promises and pitfalls, strength and weaknesses In Assessing well-being 2009 (pp. 157-180). Springer, Dordrecht.

36. Moynihan MM, Banyard VL, Cares AC, Potter SJ, Williams LM, Stapleton JG. Encouraging responses in sexual and relationship violence prevention what program effects remain 1 year later? J Interpers Viol. 2015;30:110-32.

37••. Banyard VL. Toward the Next Generation of Bystander Prevention of Sexual and Relationship Violence Action coils to engage communities. Springer, 2015, ISBN 978-3-319-23170-9.This book informs the current review by 1) providing a framework to inform bystander evaluation research toward violence prevention, 2) integrating research addressing who helps others and under what conditions, and 3) by outlining a strategic plan for new research approaches and practices. 